\title{
UNIVERSIDADE E EDUCAÇÃO BÁSICA: OS GRUPOS DE PESQUISA E EXTENSÃO POPULAR*
}

Gercina Santana Novais

Olenir Maria Mendes

\section{Considerações preliminares}

Em tempos de pandemia no Brasil e no mundo, momento de forte luta contra a Covid-19, uma doença causada por um vírus (Sars-Cov-2) ${ }^{1}$ que tem devastado o mundo, e de aprofundamento das desigualdades sociais provocado pela continuidade do capitalismo e do patriarcado, nos propusemos a escrever sobre francas possibilidades de aproximação entre a Universidade e a sociedade, mais especificamente a educação básica. Vivemos em um tempo que deixa marcas profundas em nossa história. Estamos falando do tempo em que o grande capital econômico se viu obrigado a parar parcela de suas ações, sem se comprometer com a destinação de lucros acumulados para preservar a vida de grupos historicamente excluídos, como já denunciado pelos movimentos sociais e pesquisadores/as do campo popular, vinculados à construção e avanço da democracia social. O vírus mais famoso do mundo nos fez parar, em contexto de vigência de um sistema que explora e hierarquiza as vidas.

Nesse contexto, tivemos que parar e continuar a defender que o Estado deve se colocar em movimento para garantir a vida de todas as pessoas. Não há nada maior no mundo do que a defesa da VIDA.

Paramos e revisitamos a profecia de Raul Seixas, em sua canção lançada em 1977, O dia em que a terra parou (Raul Seixas - LP 1977). Podemos sim fazer uma analogia com trechos da sua canção que é a nossa realidade hoje. Segundo Raul Seixas,

\footnotetext{
*DOI - 10.29388/978-65-86678-84-0-0-f.43-62

${ }^{1}$ Sars-Cov-2 "severe acute respiratory syndrome coronavirus 2", Síndrome Respiratória Aguda Grave do Coronavírus 2". O Sars-Cov-1 (ou apenas Sars) é o nome dado ao "irmão" do Sars-Cov-2, que causou uma epidemia na China em 2002. Esse vírus tem sido responsável pela morte de mais de 180.000 pessoas no mundo e dessas, 2.800 no Brasil. Enquanto construímos esse artigo os números de mortes continuam a crescer.
} 
Essa noite eu tive um sonho de sonhador

Maluco que sou, eu sonhei

Com o dia em que a Terra parou

Com o dia em que a Terra parou

Foi assim

No dia em que todas as pessoas

Do planeta inteiro

Resolveram que ninguém ia sair de casa

Como que se fosse combinado em todo o planeta

Naquele dia, ninguém saiu de casa, ninguém

O empregado não saiu pro seu trabalho

Pois sabia que o patrão também não 'tava lá

Dona de casa não saiu pra comprar pão

Pois sabia que o padeiro também não 'tava lá

[...]

E nas Igrejas nem um sino a badalar

Pois sabiam que os fiéis também não 'tavam lá

E os fiéis não saíram pra rezar

Pois sabiam que o padre também não 'tava lá

E o aluno não saiu para estudar

Pois sabia o professor também não 'tava lá

E o professor não saiu pra lecionar

Pois sabia que não tinha mais nada pra ensinar

[...] E o paciente não saiu pra se tratar

Pois sabia que o doutor também não 'tava lá [...]

Talvez, Raul Seixas, ao escrever a profecia, não tenha se ocupado de outras dimensões do fato anunciado, um dia a terra parou, pois, as pessoas combinaram de não sair de casa; profecia esta que revela certa urgência de refletirmos sobre ações cotidianas e uma possibilidade de recusar o programado. Uma dessas outras dimensões do processo de reflexão dessa narrativa se refere ao processo de produção da existência decorrente do sistema vigente, capitalista, racista e patriarcal. Esse sistema criador de desigualdade de classe, gênero, raça e etnia, dentre outras, provoca condições diferentes para a tomada de decisão sobre sair ou não de casa.

O que se percebe, por exemplo, no Brasil, em tempos de pandemia, é o aprofundamento da violação dos direitos humanos da maioria da população, constituída de pobres, pretos/as e mulheres das classes populares. Essa população não tem tido a chance de optar por não sair de casa e manter as condições de sobrevivência. E, quando permanece em 
casa, as condições de moradia não permitem manter o exigido pela Organização Mundial da Saúde - OMS. Não possui recursos financeiros para alimentar-se, quitar serviços de água, energia elétrica, cuidar da saúde etc. Tampouco o Estado tem assumido o papel de preservar a vida dessa população. São os interesses do mercado que permanecem.

Essa é realidade vivida por nós hoje, outubro de 2020, em plena pandemia mundial e em meio mais de 150.000 mortes no Brasil. Mas, a certeza da subnotificação, nos permite afirmar que, infelizmente, a realidade de mortes é, ainda, maior. Não há vagas em hospitais e cenas dolorosas foram produzidas, enterros coletivos, inclusive com caixões em cima uns dos outros, em uma única vala, sem a presença das famílias, mortes por falta de Unidade de Tratamento Intensivo - UTI. Tempos de dores, sofrimentos, tristezas, doenças, quarentena e aumento da população sem acesso aos alimentos. Essa dura realidade nos afeta significativamente. Mas, é importante reafirmar que os efeitos da pandemia não são iguais para todos/as. A maioria da população depende do emprego e do salário para sobreviver. Entretanto, segundo a Oxfam Brasil²,

As maiores empresas do mundo poderiam ter uma grande reserva financeira em mãos quando a crise da COVID-19 eclodiu para proteger os trabalhadores, ajustar seus modelos de negócios [...]. A década passada foi a mais lucrativa da história para as maiores empresas do mundo. Os lucros auferidos pelas empresas listadas na Global Fortune 500 aumentaram em 156\%, de US\$ 820 bilhões em 2009 para US\$ 2,1 trilhões em 2019. O crescimento dos seus lucros foi muito maior que o do PIB mundial, permitindo que elas capturassem uma fatia cada vez maior do bolo econômico global.

[...] seis meses após a Organização Mundial da Saúde ter declarado que a COVID-19 é uma pandemia, mais de 800.000 pessoas perderam suas vidas em decorrência da doença. Estima-se que 400 milhões de pessoas, a maioria mulheres, perderam seus empregos. Até meio bilhão de pessoas poderá ter sido empurrado para uma situação de pobreza até a pandemia acabar" (OXFAM, 2020, p. 5) ${ }^{3}$.

\footnotetext{
"“A Oxfam Brasil, uma organização da sociedade civil brasileira, criada em 2014, faz parte de uma rede global, a Oxfam". Disponível em: https://www.oxfam.org.br/historia/. Acesso em: 5 set. 2020

${ }^{3}$ Disponível em:

https://d335luupugsy2.cloudfront.net/cms\%2Ffiles

\%2F115321\%2F1599751979Poder_Lucros_e_a_Pandemia_-_completo_editado_-_pt-BR.pdf. Acesso em 11 set. 2020.
} 
Nessa conjuntura continuam a proliferação das tentativas de destruição de instituições públicas e a recusa das epistemologias vinculadas à valorização dos saberes produzidos por diferentes sujeitos e a favor de uma nação soberana. Mas, a narrativa recorrente da mídia conservadora é a de que teremos "um novo normal", após a pandemia.

O que significa essa expressão? Mudança de hábitos de higiene? Uso contínuo de máscara em espaços públicos? A continuidade da vigência da Emenda Constitucional 95/2017, uma reforma fiscal que congelou e reduziu investimentos em educação, saúde e assistência social por vinte anos? A aceitação de que não são todas as vidas que valem? A continuidade dos aplausos para um sistema que não humaniza? A desvalorização da produção de conhecimento desenvolvido pelas universidades públicas e a legitimação de que é humano não disponibilizar vacinas criadas, para imunizar todas as pessoas? A inclusão da solidariedade como ato indicativo de processos civilizatórios?

Outro aspecto em relação ao uso recorrente da expressão "um novo normal" se refere à tentativa de inserir o debate sobre as desigualdades sociais e impactos da pandemia no campo de defesa de que as transformações sociais não estão vinculadas à denúncia e construção coletiva de outro jeito de produzir a existência.

Argumentamos que as transformações necessárias para alterar condições de vida indigna não são consequências automáticas da vivência da pandemia. Isso porque a práxis transformadora requer tomada decisão vinculada ao projeto de humanização e recusa de qualquer sistema marcado pela exploração, destruição da natureza e impossibilidade de conviver em paz. Opção por recusar processos de exploração e condições indignas de vida. Essa tomada de decisão requer, também, olhares atentos e reflexivos sobre experiências que contêm elementos importantes para a reflexão sobre a produção de conhecimentos e modos de conhecer favoráveis à educação que humaniza.

Nessa perspectiva, crescem em importância, por exemplo, experiências do Grupo de Estudos e Pesquisas em Avaliação Educacional (GEPAE) e do Grupo de Pesquisa em Educação e Culturas Populares- GPECPOP, vinculados ao Programa de Pós-Graduação em Educação da Faculdade 
de Educação da Universidade Federal de Uberlândia, buscando fomentar a produção de conhecimentos com as Redes Públicas de Ensino Básico e os movimentos que lutam por democratizar processos de escolarização (acesso, permanência e conclusão com qualidade social) e fomentar processos educativos e formativos em contextos escolares e não escolares, em oposição ao projeto de educação hegemônico.

Nossas concepções também nos levam a fazer escolhas políticas e por isso nossas trajetórias profissionais são marcadas por práticas acadêmicas e pedagógicas que sempre procuram levar em conta a relação não hierarquizada entre Universidade e as comunidades sociais, em especial, as comunidades populares, a classe trabalhadora, uma classe que luta historicamente por direitos mínimos e resiste contra a barrocada capitalista que teima em arrancar o mínimo do mínimo, garantindo o luxo e a concentração das riquezas produzidas pelas mãos das classes trabalhadoras. É essa classe que sofre diretamente as consequências da pandemia vivida nesse ano no Brasil e no mundo. A preocupação com a comunidade social, para além dos muros da Universidade, sempre foi uma constante durante o processo de constituição e vivência no interior dos grupos de pesquisas e extensão, GEPAE e GPECPOP. Procuramos compreender a nossa realidade ampliando-a a fim de percebê-la em suas nuances e transformá-la, a partir de ações coletivas.

Outro elemento característico sempre foi o engajamento político acerca da questão social. Temas como injustiças sociais, direitos humanos, machismo, racismo, violência contra as crianças, mulheres, pobres, educação popular, escolarização das classes populares, dentre outros, sempre permearam as temáticas e o olhar de cada pessoa participante do processo de construção de projetos sejam de extensão e pesquisa e, claro, nossas práticas pedagógicas na docência. A temática exclusão social e, em especial, exclusão escolar tem sido uma marca desses dois grupos com trajetórias, marcadas pelo engajamento social e intrínseca relação Universidade e comunidade, que compartilharemos aqui. 


\section{O Grupo de Estudos e Pesquisas em Avaliação Educacional}

(GEPAE): chão batido por pés que caminham juntas

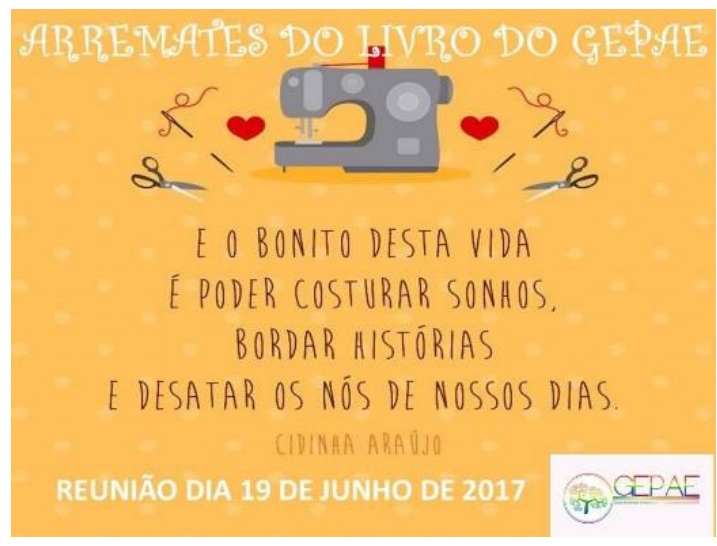

A característica mais forte, ao longo de nossos vinte anos de história, sempre foi o trabalho coletivo. Fazer junto. Por isso, os encontros, as reuniões têm sido uma prática constante em nossa história. A primeira delas ocorreu em casa, durante a minha primeira licença maternidade em função da chegada do meu filho mais velho, agosto de 2000. Receber em minha casa estudantes de pedagogia para uma visita e para uma proposta inusitada: constituir um grupo para estudar sobre o tema avaliação. E essa foi nossa primeira reunião. Três estudantes de pedagogia interessadas em continuar estudando avaliação da aprendizagem. Resultado dos estudos que fizemos na disciplina Didática no ano anterior. Eu aceitei de pronto e começamos a estudar juntas o tema avaliação da aprendizagem e até hoje não paramos. Naquele dia não sabíamos que daquele chão tão caseiro, familiar de um pequeno apartamento nasceria algo tão profundo.

De início, as intenções eram singelas: estudar e aprender mais sobre avaliação da aprendizagem. Ler junto autores e autoras que pudessem nos ajudar. Com o passar do tempo, o grupo foi ampliando-se com a participação de professoras da rede pública estadual, particular e logo também da rede municipal. Estudantes de outras licenciaturas e outros professores e professoras do curso de Pedagogia também se integraram. 
As reuniões se tornaram chão fecundo de reflexões sobre a vida cotidiana das escolas públicas. A sala de aula passou a ser problematizada e fomos entendendo o papel do grupo junto às escolas. Essa realidade nos fez engajar no trabalho extensionista. O chão das escolas tornou-se lugar essencial. Como pisar nesse chão? Com certeza pensamos juntas e as ideias nasciam a partir dos encontros, das inúmeras reuniões do Gepae. Foram três grandes encontros de extensão que marcaram nossa história. No primeiro batizamos como "Vivências em formação continuada: encontros e desencontros da avaliação educacional" e os outros foram a continuidade e por isso se tornaram a versão I, II e III (2007, 2009 e 2014). Todos com o apoio do Programa de Extensão Integração UFU/Comunidade - PEIC/UFU.

O primeiro deles ocorreu com a participação da FACED/UFU; FACIP/UFU; Faculdade Católica de Uberlândia; ESEBA/UFU; EMEI Grande Otelo; EMEI Planalto; EMEI Raimundo Vieira da Cunha e a Escola Municipal Boa Vista. Esse projeto trouxe a simbologia dos passos, pegadas, marcas...Trouxemos docentes para a Universidade a fim de refletir sobre as marcas da avaliação em nossa história pedagógica. Foram duas semanas de encontros, a partir de linguagens diferentes das artes, como modelagem com argila, encenação, músicas, poesias refletimos sobre o chão da escola pública em nossa cidade. Foi um processo de reflexão e construção de possibilidades para uma prática libertadora no campo da avaliação educacional.

Recebemos as pessoas participantes procurando explorar ao máximo suas impressões, lembranças e experiências avaliativas vivenciadas ao longo da vida escolar, seja como estudantes, seja como docentes. Por meio de desenhos, músicas, argila e pintura, propiciamos uma vivência de situações e sentimentos que trouxessem à tona as experiências avaliativas mais marcantes, fossem elas positivas ou negativas. Realizamos a técnica de grupo focal, com perguntas que possibilitaram a reflexão sobre as práticas avaliativas, as quais foram apresentadas simbolicamente através de "pés" representando a caminhada construída historicamente sobre avaliação. O curso aconteceu através de nove encontros com as seguintes temáticas:

- Impressões e expressões acerca da avaliação educacional;

- Avaliação e ideologia: a lógica excludente da avaliação na relação com a lógica escolar;

- A cultura da avaliação: nota, reprovação e classificação; 
- Os instrumentos clássicos de avaliação: a prova em destaque;

- $\quad$ Avaliação Sistêmica;

- Planejamento e avaliação

- $\quad$ Avaliação formativa: experiências alternativas de avaliação;

- Relação Escola / Família e Avaliação;

- $\quad$ Avaliando a avaliação.

Foram características marcantes desses encontros a criatividade e a reflexão coletiva, evidenciadas nas narrativas das pessoas participantes:

"A riqueza nos detalhes, a interação e liberdade entre professores e alunas, formandas, preparação dos ambientes, tanto físico como emocional. Liberdade de expressão e acolhida dentre outros."

"Aprendemos muito e nos alertou como avaliar o aluno. Também a recepção foi muito carinhosa."

"O planejamento, a coerência, espírito de equipe, as temáticas interessantes, as atividades motivadoras, acolhida amorosa, o lanche delicioso!"

"Penso que não existem pontos negativos, uma vez que todo ocorrido serviu para dialogar sobre a teoria e prática."

"Estou entendendo a avaliação de uma forma mais ampla, mais crítica, como forma de reconstruir um processo de ensinoaprendizagem".

"Entendo a avaliação não como parte isolada no processo de ensino, a avaliação deve ocorrer de forma contínua no processo ensinoaprendizagem".

"A avaliação é dinâmica, inclusiva, construtiva e amorosa tendo em vista tomar uma decisão sobre o processo ensino-aprendizagem."

"Avaliação tem que se dar como um processo da aprendizagem e não isolada. Precisa ser compreendida em sua função social para mudarmos nossas ações e práticas. "

"Queremos levar para nossa escola um modelo de avaliação construtiva, crítica, reflexiva. A utopia da avaliação formativa seria realizar um trabalho coletivo, solidário e colaborativo. Ajudaremos a compor essa caminhada a partir de nossas práticas e reflexões".

"Promover estudos de avaliação com os objetivos de rever a concepção, estimular a concepção de avaliação formativa, viabilizar recursos para avaliação formativa".

"Desejamos levar que a avaliação seja um trabalho coletivo, propiciando aprendizagem ao educando, e que ao ser avaliado ele 
sinta parte do processo ensino-aprendizagem. E que todos os educadores se interajam nesse processo de avaliação mais humano, calorosa e amorosa" (RELATÓRIO, Fala das pessoas participantes, 2007.).

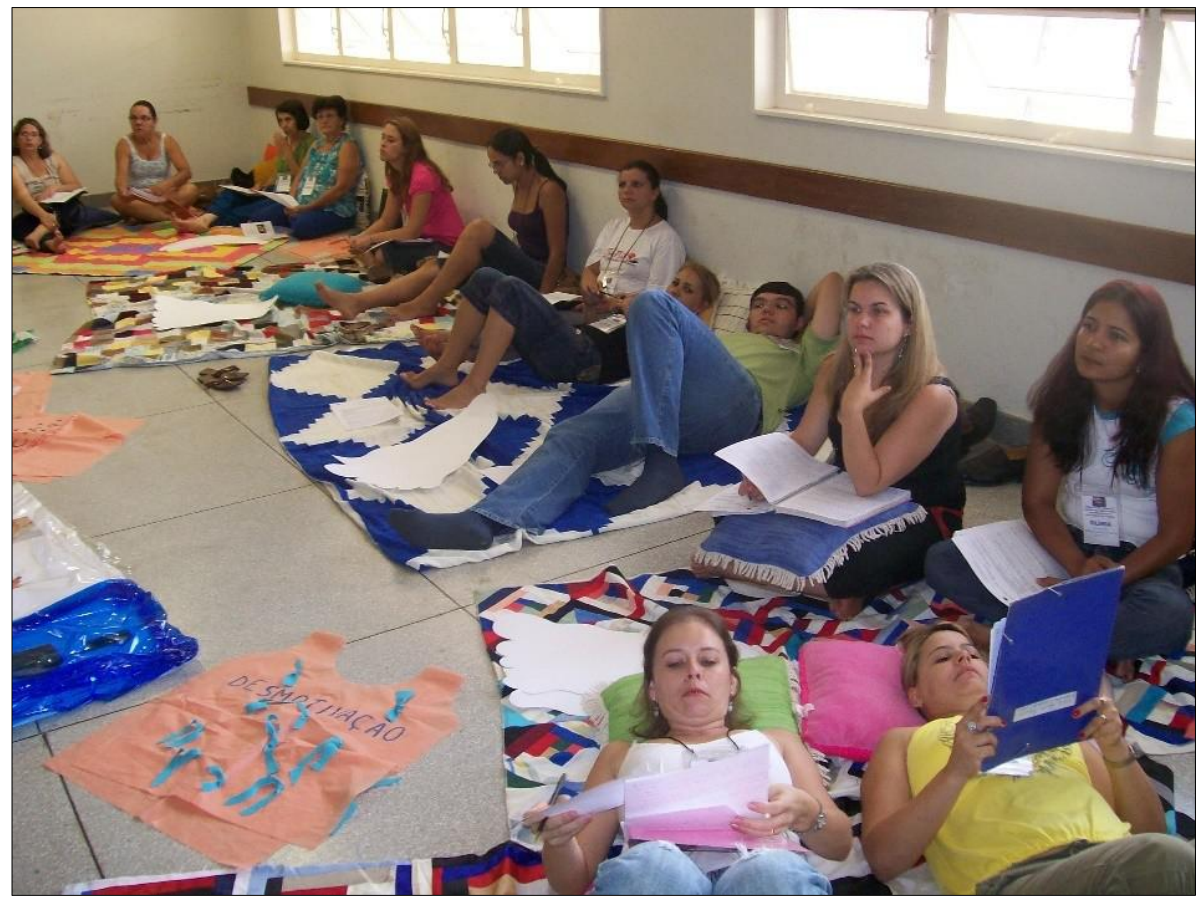

Foto 8 - 9o Encontro: Encerramento e avaliação do curso - Momento de reflexão sobre as aprendizagens - espaço decorado simbolicamente com colchas de retalho.

O trabalho coletivo sempre foi nossa escolha, assumimos práticas descentralizadoras, como: coordenações compartilhadas e rodiziadas e as deliberações de pautas, projetos em consenso. Experimentamos também as diferentes formas de registros, usualmente chamadas por nós de memórias. Nessas práticas, prevalecem a autonomia e a criatividade para registrar de diferentes formas: escrita, áudio, imagens fotográficas, entre outras, que são lidas, compartilhadas e arquivadas em sistema de armazenamento local (nuvem) e impressas em nosso portfólio coletivo, nomeado por nós como "pasta de importâncias". 
Geralmente, as reuniões têm sido recheadas de relatos (positivos e negativos) da vida escolar, ideias de superação de dificuldades e compartilhamento de boas experiências. Essas práticas contribuem para a construção coletiva das pautas, das deliberações e dos temas a serem estudados e pesquisados.

Ao longo de quase vinte anos, o grupo tem-nos deixado marcas significativas e gerado aprendizagens e diferentes níveis de mudanças em nossas vidas, seja de comportamentos, de linguagens ou mesmo de concepções. Assumimos algumas lutas e bandeiras e uma delas é a luta feminista, já que o grupo sempre foi frequentado por, quase que exclusivamente, mulheres. As lutas feministas têm gerado bonitas aprendizagens em nós!

As histórias de lutas, os encontros, as rodas de conversa, os diálogos e reflexões que têm ocorrido dentro dos espaços criados pelo Gepae e atuações em movimentos sociais solidificaram em nós uma consciência feminista e, por isso, aderimos ao movimento que se recusa a utilizar uma linguagem sexista, tanto escrita quanto falada, construída historicamente e que está presente na sociedade. Decidimos não nos calar diante dos silenciamentos impostos historicamente.

Hoje entendemos claramente que o nosso papel político é dar visibilidade às mulheres! Falar do trabalho docente é falar de uma categoria feminina. O próprio reconhecimento de Paulo Freire, em um trecho do seu livro "Pedagogia da Esperança", fortalece os nossos argumentos:

[...] eu usava, porém, uma linguagem machista, portanto discriminatória, em que não havia lugar para as mulheres. [...] Em certo momento de minhas tentativas, puramente ideológicas, de justificar a mim mesmo, a linguagem machista que usava, percebi a mentira ou a ocultação da verdade que havia na afirmação: 'Quando falo homem, a mulher está incluída'. E por que os homens não se acham incluídos quando dizemos: 'As mulheres estão decididas a mudar o mundo'? [...] A discriminação da mulher, expressada e feita pelo discurso machista e encarnada em práticas concretas, é uma forma colonial de tratá-la, incompatível, portanto, com qualquer posição progressista, de mulher ou de homem, pouco importa. [...] A recusa à ideologia machista, que implica necessariamente a recriação da linguagem, faz parte do sonho possível em favor da mudança do mundo. [...] Não é puro idealismo, acrescente-se, não esperar que o mundo mude radicalmente para que se vá mudando a linguagem. 
Mudar a linguagem faz parte do processo de mudar o mundo. A relação entre linguagem-pensamento-mundo é uma relação dialética, processual, contraditória (FREIRE, 2000, p. 66-68).

Nessa perspectiva, o nosso trabalho assume um caráter de emancipação, com a realização das potencialidades criativas humanas, ou seja, a possibilidade de criar e recriar o mundo e a si mesma/o. Isso significa pensar em duas ações: SER e FAZER, ou seja, implica não uma prática descolada do pensar, mas a práxis, que é o fazer pensado, intencional. Segundo Severino (1995), nossa prática é um processo permanente que nos põe em relação com a natureza física, de um lado, com nossas/os semelhantes, de outro, e, ainda, com nossa própria interioridade.

O nosso grupo chegou a uma compreensão da avaliação que a considera parte de um tripé inseparável. A relação aprendizagem-avaliaçãoensino é agora nossa forma de compreender e tentar praticar a avaliação e por isso assumimos no grupo o uso do termo "propostas de trabalho avaliativo" que podem ser entendidas como proposições pedagógicas para o acompanhamento das aprendizagens significativas. Para Fernandes (2016), ensino, avaliação e aprendizagem é um tripé inseparável, e o termo "proposta de trabalho" carrega em si essa relação intrínseca. Ao planejar, as/os professoras/es esperam respostas das/os estudantes que se movem de diferentes formas e se envolvem em diferentes níveis. Enfim, referem-se às ações que ocorrem antes, durante e depois dos processos de ensino, de avaliação e de aprendizagens no cotidiano pedagógico. É, na verdade, todo o esforço que fazemos, professoras/es e estudantes, para que as aprendizagens de fato ocorram.

Desenvolver pesquisa coletivamente também representou um aprendizado bastante significativo. Nossa pesquisa teve como objetivo identificar que tipo de impactos, de melhorias ou de transformações as políticas mineiras de avaliação (Simave) têm provocado nas escolas, se elas têm produzido qualidade educacional e em que perspectiva. Buscamos, ainda, entender como a Avaliação Sistêmica tem sido concebida e trabalhada pelas/os profissionais e como ocorre a construção da concepção de qualidade nesse espaço de vida e de interações. Procuramos analisar e compreender como as escolas têm se organizado, na tentativa de resolver os problemas relacionados à aprendizagem/desempenho de suas/seus estudantes, a partir da interpretação dos resultados das avaliações externas e fizemos tudo isso a partir de uma longa e lenta caminhada, característica do trabalho coletivo (MENDES, et al., 2018). 
No diálogo com a realidade, no interior das seis escolas, realizamos a observação participante, as entrevistas com professoras/es e diretoras/es, a aplicação de questionários às/aos estudantes dos terceiros e quintos anos do Ensino Fundamental I e uma amostra de seus familiares.

Nesse percurso, vivenciamos encontros e desencontros, debates, idas e vindas nos consensos, conflitos de ideias, certezas e incertezas, inseguranças, respostas e novas perguntas, além do fortalecimento de laços de amizade. Foram inúmeras rodas de conversas, em que realizamos estudos dos referenciais teóricos, dos documentos oficiais, análises das avaliações externas, edificação dos procedimentos para a construção dos dados e análises interessadas em contribuir para transformar processos desiguais de escolarização.

\section{O Grupo de Pesquisa em Educação e Culturas Populares- GPECPOP: tecendo redes de pesquisa e extensão popular}

No itinerário da criação do Grupo de Pesquisa em Educação e Culturas Populares - GPECPOP, vinculado ao Programa de Pós-Graduação em Educação da Universidade Federal de Uberlândia-UFU, destacam-se os efeitos dos acontecimentos e movimentos a favor da democratização da Universidade, da escolarização das classes populares e do desenvolvimento de projetos de educação emancipatória, vinculados à construção de uma nação soberana e com justiça social.

Esses acontecimentos e movimentos contra hegemônicos fomentaram reflexões sobre outra universidade e a necessidade de reinventar, coletivamente, modos de produzir o ensino, a pesquisa e a extensão. Por isso mesmo a luta por ensino, estruturado por pesquisa e extensão, foi atravessada pela problematização dos conceitos de extensão, de pesquisa e da função da universidade, potencializando as vozes que indagavam: educação a favor de quem? Com quem? Para quem? Qual extensão? Qual paradigma de pesquisa? Qual relação os grupos de pesquisa estabelecem com os/as participantes das investigações? Em que medida os conhecimentos produzidos pelos movimentos sociais e pelas classes populares impactam as definições dos Grupos de Pesquisa sobre temas e modos de produzir conhecimentos?

Desse modo, as lutas por empossar um reitor eleito pela comunidade universitária; democratizar os Conselhos da Universidade, 
garantindo e ampliando a participação, com poder de decisão, da comunidade interna e externa; ampliar o financiamento público e o acesso à universidade pública; transformar a relação entre universidade e sociedade e valorizar outras epistemologias e saberes produzidos em diferentes lugares, colocam em movimento outros processos educativos.

Nesse processo de denúncia e anúncio (FREIRE, 1996), cumprem papel importante os projetos de extensão popular, estruturados a partir das demandas e ou interesses das classes populares, elaborados e desenvolvidos com os movimentos sociais e educadores/as que atuam em contextos escolares e não escolares. Para refletir sobre esse tipo de extensão, Souza apresenta

[...] considerações em torno da dimensão popular atrelada à extensão, na perspectiva de Cruz (2011 e 2017). De acordo com o autor, podemos compreender a extensão popular como um trabalho social útil, desenvolvido por meio de um agir crítico estruturado na convivência, por meio de um processo dialógico e participativo, com a intenção de articular o ensino e a pesquisa na mobilização de experiências, estudos e reflexões em contextos adversos, de modo que possam ser superados os problemas sociais (e até mesmo socioambientais), a partir do compromisso e comprometimento com a mudança e o enfrentamento da exclusão social e da desumanização. Desenvolver a extensão popular pressupõe um radical objetivo de transformação das condições de opressão, de onde emergem as condições de dor, incômodo, injustiça e autoritarismo, estando assim direcionada sistematicamente para o alcance da emancipação das pessoas, do fortalecimento da alteridade e do respeito à diversidade (SOUZA, 2019, p. 250).

Nessa direção, em agosto de 2001, foi criado o Programa de Formação Continuada em Educação Popular, vinculado à Pró Reitoria de Extensão, Cultura e Assuntos Estudantis da UFU. Do processo de criação e desenvolvimento do Programa participaram membros dos movimentos populares (de luta pela terra, de defesa da saúde pública e do Sistema Único de Saúde, do direito à cidade, de educação e culturas populares, dos/as indígenas não aldeados /as, de economia solidária etc.) e dos sindicatos (defesa da educação pública, laica, democrática e gratuita), dos cursinhos alternativos populares, professores/as das redes públicas de Ensino Básico e da UFU, estudantes de diferentes licenciaturas e membros 
de Organizações Não Governamentais vinculadas, por exemplo, à luta pelo fim da violência contra as mulheres.

Nesse processo marcado pelo diálogo, o título do Programa é modificado, a metodologia de trabalho estabelecida, os temas e o tipo de participação definidos. Por conseguinte, o Programa de Formação Continuada em Educação, Saúde e Culturas Populares, com coordenação colegiada, submetida às decisões tomadas nas assembleias; roda de conversa, cortejo dos ternos de congados, exposição dialogada sobre trabalhos desenvolvidos pelos movimentos populares, místicas dos movimentos de luta pela terra, pesquisa ação emancipatória, encontros de educação, saúde e culturas populares, criação da Revista de Educação Popular, dentre outras ações, ancora-se em experiências e epistemologias diversas, afastando de um conceito de extensão que orienta ações de colonização, a partir da valorização de um determinado conhecimento e desvalorização das epistemologias, conhecimentos e experiência de determinados grupos sociais. Isso significou, também, a garantia do direito dos/as representantes dos movimentos populares e demais participantes do Programa de apresentar Projetos de Extensão à assembleia, aprovar e compor a coordenação dos referidos projetos com financiamento das ações.

A reflexão sobre a participação dos membros dos movimentos populares e de grupos historicamente excluídos no referido programa pode ser beneficiada pelas formulações de Fleuri:

Além de se constituir dispositivos institucionais que sustentem a possibilidade destes grupos se auto-organizarem, no contexto das instituições universitárias e/ou em parceria com elas, torna-se necessário desenvolver estratégias e dispositivos de mediação, que promovam e sustentem o diálogo crítico e solidário entre os diferentes grupos emergentes. Coloca-se o desafio de se potencializar e consolidar uma nova epistemologia dialógica e crítica de educação e pesquisa, de extensão e administração, que atravessa paradoxalmente a epistemologia burocrática e disciplinar, tradicionalmente predominante na constituição das práticas universitárias. Trata-se não só de reconhecer as diferentes culturas e em suas múltiplas dimensões científicas, mas, sobretudo, desenvolver processos e dispositivos complexos de mediação e diálogo entre os diferentes sujeitos socioculturais (FLEURI, 2019, p. 48). 
As experiências narradas anteriormente, os conhecimentos construídos na relação com os movimentos sociais e educadores/as da rede pública de educação básica, da UFU e de outros cantos da cidade e do campo, o desejo de incluir no Programa de Pós-Graduação em Educação da Universidade Federal de Uberlândia o ensino, a pesquisa e a extensão sobre educação e culturas populares impulsionam a criação do Grupo de Pesquisa em Educação e Culturas Populares - GPECPOP, vinculado à linha de pesquisa Saberes e Práticas educativas.

Os membros do GPECPOP, professores/as das redes de educação básica e da UFU, estudantes de diferentes licenciaturas, membros dos movimentos populares e sindicais, a partir de epistemologias marcadas por ausência de hierarquias entre sujeitos e saberes, adota uma dinâmica de trabalho coletivo, orientado pelos princípios da amorosidade, emancipação, autonomia, libertação e a valorização da vida digna de cada um/uma, e a criação de subgrupos sobre diferentes dimensões da educação e culturas populares. Privilegiou-se a Roda de Conversa como espaço formativo, de partilha, produção e análise de dados, e o uso de registro escrito e fotográfico do ocorrido nesse espaço. E adotou-se a teia como inspiradora do modo de produzir conhecimentos.

A maioria dos projetos de pesquisa e extensão popular desenvolvidos contemplou as seguintes etapas:

1a Etapa: diagnóstico - escuta e análise das demandas e delimitações dos problemas de pesquisa; definição dos possíveis locais para realização da pesquisa; desenho da teia, colorindo os fios, evidenciando entrelaçamentos e vínculos e elaboração e desenvolvimento do projeto, contemplando vários itinerários e portas de entrada. 2a Etapa: criação de comunidades de discussão e de intervenção ${ }^{4}$.

Dessa forma, a tomada de decisão sobre o local e o tema dos projetos de pesquisa com extensão foi ancorada na análise das demandas recebidas pelo Grupo. A título de ilustração, é importante mencionar o Projeto "Rede de Educação Popular", um projeto guarda-chuva de pesquisa e extensão, constituído de cinco subprojetos articulados, como foco na educação e culturas populares como estratégias de inclusão escolar e

\footnotetext{
${ }^{4}$ Disponível em: http://www.gpecpop.faced.ufu.br/node/28. Acesso em: 12 out. 2020
} 
social, desenvolvido no período de 2009 a 2011. O Projeto almejava os seguintes objetivos ${ }^{5}$ :

- Identificar e analisar em diferentes contextos educativos os saberes e as expressões culturais, com vista a conhecer e desvelar os significados e os sentidos destes para a inclusão social e/ou escolar de grupos historicamente excluídos, potencializando redes de investigação e de intervenção sobre educação e culturas populares.

- Identificar e divulgar práticas de educação e culturas populares e seus significados para a inclusão social e ou escolar das classes populares.

- Investigar a produção de situações de sucesso e fracasso escolar das classes populares.

- Investigar processos de escolarização das classes populares.

- Refletir sobre relações entre gênero, raça/etnia, classes sociais, educação e culturas populares.

- Refletir sobre diferentes dimensões que se entrecruzam na produção de sentido e na constituição da teia da educação e culturas populares e suas relações com a inclusão social e escolar das classes populares.

solidária.

Refletir sobre educação popular em contextos de economia

- Investigar e intervir em diferentes contextos educativos com vistas a favorecer inclusão social/escolar.

- Desenvolver formação continuada em educação e culturas populares para educadores(as) por meio da organização e desenvolvimento de sessões reflexivas.

- $\quad$ Construir e disponibilizar banco de dados sobre educação e culturas populares no município de Uberlândia.

- $\quad$ Planejar e implementar espaços de divulgação e debate sobre os resultados da pesquisa-ação.

- $\quad$ Publicar um livro sobre educação e culturas populares em diferentes contextos educativos. projeto.

- Participar de eventos científicos, divulgando resultados do

- $\quad$ Promover um evento sobre educação e culturas populares.

- $\quad$ Criar vídeo-formação. (Plano de Trabalho do Projeto, 2009).

\footnotetext{
${ }^{5}$ Fonte: Plano de Trabalho do Projeto: Rede de Educação Popular. Coordenação: Benerval Pinheiro Santos e Gercina Santana Novais. UFU, 2009. (texto digitado e não publicado).
} 
O GPECPOP promoveu Encontros Nacionais de Educação, Saúde e Culturas populares com os movimentos populares, sindicatos, associação de moradores; Núcleo de Pesquisas e Estudos em Educação Matemática/UFU- Ituiutaba - Uberlândia-MG, Central de Movimentos Populares - Triângulo Mineiro e Alto Paranaíba, Organizações Não governamentais e Grupos de Estudos e Pesquisas. Esses encontros criaram espaços para a comunicação e reflexões sobre conhecimentos produzidos, por exemplo, pelos movimentos sociais e grupos de pesquisa das universidades, em contextos escolares e não escolares, e celebrações das culturas populares. É fundamental rememorar que

[...] os movimentos sociais, assim como diferentes instituições da sociedade civil, vêm se assumindo não mais como simples consumidores de conhecimento produzido pelas pesquisas realizadas na universidade, nem apenas como assimiladores dos profissionais por ela formados. Os movimentos e a instituições sociais vêm se revelando como agentes autônomos, produtores de conhecimento e promotores de propostas políticas. Desta forma, adotam uma postura proativa de diálogo crítico e criativo com os diferentes agentes sociais, inclusive com a universidade. Reivindicam uma relação de reciprocidade, recusando a subalternidade, ao problematizar e transformar o contexto sociocultural e ambiental em que se constituem (FLEURI, 2019, p.15).

No ano de 2011, o Grupo promoveu o ENPECPOP - Encontro Nacional de Pesquisadores/as em Educação e Culturas Populares, orientado pelo tema "Educação e Culturas Populares: produção de conhecimento e superação das desigualdades no Brasil", contemplando comunicações vinculadas aos 10 eixos temáticos: escolarização das classes populares e educação popular; culturas populares, democracia e identidade; relações de gênero, raça e etnia; meio ambiente, desenvolvimento popular e cidadania; educação popular: etnociências; Educação popular e saúde; movimentos sociais, educação e culturas populares; educação de jovens e adultos; tecnologias, comunicação e informação na educação popular; infâncias e educação popular.

Em 2013, o tema do 20 ENPECPOP foi "Educação e Culturas Populares: Direitos Humanos, Saberes e Resistências". Além dos eixos temáticos presentes no primeiro encontro, foram acrescidos: educação, trabalho, movimentos sociais e cidadania e educação Popular e artes. 
Há, contudo, outro aspecto que devemos destacar. Essas experiências narradas, envolvendo extensão popular e pesquisa, também, implicaram a reflexão sobre o ensino, colocando a urgência de incluir novos temas, metodologias e epistemologias nos cursos de graduação e pósgraduação, bem como conhecimentos, culturas e a história de seus/suas produtores/as, vinculados às classes populares e à periferia do sistema vigente. Implicaram também na valorização da diversidade de linguagens e modos de divulgar conhecimentos em espaços de comunicação de produção científica e colocou a palavra ciência no plural. Esse processo reflexivo mostrou, também, que as relações não hierarquizadas entre universidade e sociedade têm centralidade na construção de uma educação que emancipa e humaniza.

\section{(In) conclusões}

Este texto foi elaborado durante a ocorrência de pandemias. De fato. A pandemia provocada pela Covid-19, uma doença causada por um vírus (Sars-Cov-2) é uma das pandemias. Outras podem ser mencionadas e são responsáveis por aprofundar as desigualdades sociais. São pandemias que retiram a condição de vida digna para a maioria da população e colocam em risco a natureza e a vida humana. A título de ilustração dessas pandemias, citamos:

a) depredação da natureza;

b) aumento da fome no mundo e do desemprego estrutural.

c) aumento das grandes fortunas e dos lucros dos bancos;

d) redução do papel do Estado na garantia de direitos sociais e humanos;

e) ensino remoto propagado como oportunidade de continuidade dos estudos dos/as alunos/as das escolas públicas combinado com a invisibilidade da realidade vivida por parcela significativa desses alunos/as. Esses alunos/as não têm acesso à rede de internet. Os pais, as mães e outros/as responsáveis não têm possibilidade de deixar trabalhos, embora mal remunerados e precarizados, para orientar atividades prescritas e disponibilizadas pela escola;

f) fortalecimento da educação bancária (FREIRE, 1996), composta por um conjunto de aulas vendidas como a melhor e a nova educação, devido à adoção de tecnologias de informação e comunicação. 
Tendo em vista o exposto, a nosso ver, cresce em importância a disputa por outros projetos construídos nos movimentos de resistência e proposição. Nesse processo, as experiências dos Grupos de Pesquisa, materializadas em projetos de pesquisa e extensão popular, podem oferecer elementos para pensarmos a relação entre a universidade e a sociedade, os processos de produção, acesso e comunicação de conhecimentos e culturas necessários para enfrentarmos os efeitos das pandemias e dos processos desumanizadores, fortalecendo a construção de novos modos de produzir a existência humana.

Nessa perspectiva, em relação aos desafios relativos ao aprofundamento das desigualdades na escolarização das classes populares, um direito social e humano, as experiências dos Grupos de Pesquisa e Extensão Popular têm potencial para nos auxiliar a desenhar relações não hierarquizadas e solidárias entre universidades e outras instituições educacionais escolares e não escolares e desenvolver outras ações coletivas e democráticas, com vistas à ampliação da definição e do reconhecimento das aprendizagens, ocorridas durante a pandemia provocada pela Covid-19, e à urgência de continuar ensinando que todas as vidas importam.

\section{Referências}

BRASIL. Emenda Constitucional no 95, de 15 de dezembro de 2016. Altera o Ato das Disposições Constitucionais Transitórias para instituir o Novo Regime Fiscal e dá outras providências. Disponível em: http://www.planalto.gov.br/ccivil_03/constituicao/emendas/emc/ emc95.htm. Acesso em: 11 set. 2020.

FLEURI, Reinaldo Matias. Conversidade: diálogo entre universidade e movimentos sociais. João Pessoa: Editora do CCTA, 2019.

FERNANDES, Domingos. Ensino e avaliação no ensino superior: reflexões a partir da pesquisa realizada no âmbito do projeto AVENA. Cad. Cedes, Campinas, v. 36, n. 99, p. 223-238, maio-ago., 2016.

FREIRE, Paulo. Pedagogia da Autonomia - Saberes necessários à prática educativa. São Paulo: Paz e Terra, 1996. 
FREIRE, Paulo. Pedagogia da Esperança - um reencontro com a pedagogia do oprimido. Rio de Janeiro: Paz e Terra, 2000.

MENDES, Olenir Maria Mendes; RICHTER, Leonice Matilde; MARTINS, Christian Alves; CAMARGO, Clarice Carolina Ortiz de; COSTA, Simone de Freitas Pereira. (org.). Pesquisa coletiva, avaliação externa e qualidade da escola pública. 1. ed. Curitiba: CRV, 2018.

OXFAN BRASIL. Poder, lucros e a pandemia: Da distribuição excessiva de lucros e dividendos de empresas para poucos para uma economia que funcione para todos. Disponível em: https://www.oxfam.org.br/historia/. Acesso em: 5 set. 2020

SOUZA, Tiago Zanquêta de. A extensão popular e a produção do conhecimento conversitário. Cad. Pesq., São Luís, v. 26, n. 2, p. 237-256, abr./jun., 2019. Disponível em:

http://www.periodicoseletronicos.ufma.br/index.php/ cadernosdepesquisa/article/view/1189 5/6623. Acesso em: 11 out. 2020. 